\title{
Diversity in Health Care: A Case of Diversity in Long-Term Care
}

\author{
Ron Fuqua \\ Ph.D., MBA, Associate Professor \\ Department of Health Care Management \\ College of Health, Clayton State University \\ Thomas McIlwain \\ Ph.D., MPH, Professor \\ Department of Health Care Management \\ College of Health, Clayton State University \\ Kendolyn Smith \\ PharmD, MS, Assistant Professor \\ Department of Health Care Management \\ College of Health, Clayton State University \\ Latrina Walden \\ RN, MHA, Lecturer \\ Department of Health Care Management \\ College of Health, Clayton State University
}

\begin{abstract}
Achieving diversity is a necessity in any organization but is especially important in long-term care. The care delivered is to a diverse group of patients and their families. Therefore, this case allows the analysis of diversity in one long-term care company. While Federal EEO requirements include a report of diversity annually for employers and contractors, this is a further analysis of the diversity data used for reporting. Looking into frequency and distributive statistics allows a better understanding of the diversity of this company.
\end{abstract}

\section{INTRODUCTION}

Diversity and cultural competency are recognized as some of the most significant multifaceted issues facing the nation's health care system because they can affect both quality and access to care (Weech-Maldonado, et al., 2002). Achieving diversity continues to be one of the largest human resource management problems among health care organizations. In the long-term care arena, diversity can be an even more exacerbating problem. The limitations include the population diversity from which employees come. In addition, the development and implementation of corporate HR policies directly impact the level of diversity achieved.

This case study calculates and analyzes the diversity of a vertically integrated long-term care organization operating in multiple states and employing over 13,000 employees. The vertically integrated health care companies include home health care, hospice, rehabilitation, skilled nursing, medical supply, pharmacy, and the corporate entity. In this case, the data collected were for use in the annual EE01 report and during a consulting engagement.

Data were collected using the standard Equal Employment Opportunity Commission terms and methods for the creation of the organization's annual EE01 report. Further analysis using frequency and distribution-oriented statistics allowed a more in-depth review of this 
organization's level of diversity in each of its vertically integrated companies. The second level of analysis using comparative statistics allowed the illustration of the internal level of consistency within the organization. The implications of the results are discussed in relation to the goals of diversity management in healthcare.

\section{REVIEW OF THE LITERATURE}

Diversity issues in the healthcare system are the result of many demographic, social, and cultural factors. With significant changes of the U.S. population, including the aging population, and cultural and racial composition, healthcare organizations must work to ensure the workforce, both managerial and clinically, represents the demographics of these evolving dynamics (Institute of Medicine, 2004). The IOM study related to clinical training found that racial and minority health care professionals will more likely serve racial and minority clients. It also reported that minority patients will choose minority healthcare professionals if given a choice (Institute of Medicine, 2004). These factors can have a significant effect on the quality of outcomes of health services.

Healthcare professionals can no longer ignore diversity because patients present varied perspectives, values, beliefs, and behaviors regarding health and well-being (Betancourt, et al., 2013). The Office of Minority Health developed a list of standards of Culturally and Linguistically Appropriate Services (CLAS) that were expanded in 2013 to ensure equal access to quality health care by diverse populations (United States Department of Health and Human Services, Office of Minority Health, 2013). These standards include the following:

\section{Principal Standard}

1. Provide effective, equitable, understandable, and respectful quality care and services that are responsive to diverse cultural health beliefs and practices, preferred languages, health literacy, and other communication needs.

\section{Governance, Leadership and Workforce}

2. Advance and sustain organizational governance and leadership that promotes CLAS and health equity through policy, practices, and allocated resources.

3. Recruit, promote, and support a culturally and linguistically diverse governance, leadership, and workforce that are responsive to the population in the service area.

4. Educate and train governance, leadership, and workforce in culturally and linguistically appropriate policies and practices on an ongoing basis.

Standard 3, "Recruit, promote and support a diverse governance, leadership, and workforce," is especially difficult in health care services. Many hospitals around the country have pledged to increase diversity on their boards and management and provider ranks, and they have created chief diversity officers to oversee the process, but analysis shows that healthcare is still predominantly white (Betancourt, et al., 2013). Previous literature suggests that racially and ethnically diverse business organizations outperform their more homogenous counterparts in both quality and financial outcomes (Health Literacy: A Prescription to End Confusion, 2004).

The Institute for Diversity in Health Management (2018), an affiliate of the American Hospital Association, recognizes that diversity starts at the top of every organization in the C-Suite and filters down into the front-line staff caring directly for patients. There is little research that exists on the impact that the role of leadership plays in addressing health disparities from a healthcare management perspective; however, much of the research is geared towards addressing the bias of the providers, i.e., physicians treating patients of color within the 
healthcare setting (Noble, D., Greenhalgh, T., Casalino, L., 2014). The available research that is geared specifically to address diversity within the management ranks aims at providing strategies to assist in implementation.

The American Hospital Association launched the \#123forEquity pledge campaign in 2015 to eliminate healthcare disparities. Part of that pledge asks the signers to increase diversity in leadership and governance. Only 1500 of the 5000 U.S. hospitals actually signed the pledge. According to the AHA's Institute for Diversity and Health Equity, in 2015, only 14 percent of hospital board members and 9 percent of CEO's are minorities. Since 2013, this number has not increased despite the efforts. Minorities now represent 11 percent of executive leadership positions in hospitals while minorities constitute about $1 / 3$ of the hospitals' patient population (Institute for Diversity, 2015). With the passage of healthcare reform, minorities are 48 percent of the 32 million that are newly insured according to an IOM report (Betancourt, et al., 2013).

While empirical data is limited, there have been some studies that have delved further into the patient care side of the arena. A 2003 study by researchers at the Johns Hopkins University School of Medicine (Cooper, L.A., Roter, D.L., Johnson, R.L., Ford, D.E., Steinwachs, D. M., \& Powe. N. R.) found that African Americans who saw physicians of the same race were more satisfied and rated their physicians as more participatory than patients who visited doctors of a different race. In addition, a 2004 report by the Sullivan Commission on Diversity in the Healthcare Workforce, discovered that the lack of diversity among healthcare professionals might be a greater cause of disparities in access and outcomes versus the lack of health insurance (Sullivan Commission, 2004). To further illustrate, the Institute of Medicine report found that even with the same insurance and socioeconomic status, controlling for comorbidities, stage of presentation, and other confounders, minorities often receive lower quality healthcare than their white counterparts (Institute of Medicine, 2003).

A key component to these disparities is trust. Trust is the foundation upon which healthcare is based. Research tells us that patients who mistrust their healthcare providers are less satisfied with the care that they receive, and mistrust of the healthcare system greatly affects their use of services (Sullivan Luallin Group, 2013). Lack of confidence in physicians results in inconsistent care, doctor shopping, self-medicating, and increased patient demand for referrals and diagnostic tests (Sullivan Luallin Group, 2013). African-American mistrust of providers is rooted in history. U.S. Public Health Service exploitation of African-Americans in the Tuskegee study left a legacy of mistrust that persists even today. This lack of trust is perpetuated in today's healthcare environment, even evident when research is done. African-Americans report less trust in their healthcare providers and are more likely to perceive discrimination in healthcare (Sullivan Luallin Group, 2013). While language barriers have not even been mentioned, they suffer the same unsatisfactory feeling if there is a language barrier.

Identifying root cause is key to explaining the problems of lack of diversity in healthcare from the C-suite to the frontline staff. Cultural competence is a key driver, or lack thereof, to the reasoning behind a weak display of diversity in healthcare; therefore, cultural competence is the ultimate goal. Some scholars and practitioners involved in this debate believe that diversity management is the process leading to culturally competent organizations (Wilson-Stronks, A., and Mutha, S. 2010). Organizations should become culturally competent and invest in diversity, and it begins with leadership. Shifting the demographic landscape of the healthcare workforce and becoming culturally competent as a global and consumer-driven organization that is reflective of the population will be key to improving relationships with the community and overall organizational success. 


\section{OVERVIEW OF LONG TERM CARE}

Long-term care focuses on patients who stay on an average of more than 30 days. During the patient's stay there are various health professionals that work collaboratively to provide care for the patient. In long-term care facilities, the following skilled professionals provide tiered levels of care. In each of these roles there are some observations regarding the diversity of professionals within the role. As with most professions, health care is one of those in which there are variations based on race, gender and education. According to the Bureau of Labor Statistics (2000), there is approximately 1.85 million employees working in facility -based home care settings. With so many professions that complete the spectrum within the long-term care environment, the concept of diversity carries many descriptions. Race/ethnicity, gender, and culturally competent care among professionals are all extremely important to maintaining quality care for patients now and in the future.

There are a large number of professionals that make up the LTC workforce. Specifically, there are Licensed Professionals and Paraprofessionals. Licensed professionals include: Medical Doctors (MD), Pharmacists (PharmD), Nurse Practitioners (NP), Physician Assistants (PA), Registered Nurses (RN), Licensed Practical Nurses and Vocational Nurses (LPN and LVN). Nursing is one of the largest areas within LTC. In addition, there are Administrators, Directors and CEOs who are vital to the daily operation of long-term care facilities. Long-term-care facilities must have a physician Medical Director who is responsible for policies and coordinating care. However, few of the physicians are geriatricians, within or outside of the LTC system, nor have they had training in geriatrics to prepare them to carry out many of the roles.

A published report focusing on the racial and ethnic diversity in the LTC workforce was completed by UCSF Health Workforce Research Center, and they identified the need for increasing diversity within the workforce in order to ensure that clients receive care from persons who mirror their race or ethnicity. The 2015 American Community Survey revealed that there is an inverse relationship between the education attained and the racial/ethnic diversity (Bates, T., Amah, G., Coffman, J., 2018). Following is a description of the various professional and paraprofessionals that work in LTC.

\section{Licensed Nurses}

Registered Nurses (RNs) are the largest segment of health professionals, and 48\% of them work in general medicine hospital. Most of the others work in doctor's offices, specialized hospitals, nursing homes and home health agencies (DuPre', 2016). According to the American Nurses Association, Nurses must all be licensed through their state in order to practice as a nurse. There are many paths to becoming a licensed nurse. Nurses may pursue an Associate degree in nursing (ADN) which is a 2-year degree or a Bachelor of Science in Nursing (BS/BSN) which is a 4 year degree. Graduate level education enhances the expertise of a licensed nurse with option to complete a Master of Science in Nursing (MSN) PhD (Doctor of Philosophy) and DNP (Doctor of Nursing Practice). Licensed practical nurse (LPNs) and Licensed vocational nurse (LVNs) positions usually require a year or so of specialized training after high school. The number of jobs for RNs is expected to grow 26\% between 2010 and 2020 (DuPre', 2016).

In most long-term care facilities, the nurse collaborates with physicians, social workers, dieticians, speech language pathologists, physical therapists, occupational therapists, case managers, pharmacists, respiratory therapists, and other members of the interdisciplinary team. The interdisciplinary team is necessary in long-term care due to the elaborate 
complexity and extent of patient issues that now manifest in this setting. Long-term care nurses care for patients across the life span with numerous afflictions and diagnoses, although the majority of the patients are elderly. Patients with chronic disease processes such as hypertension, coronary artery disease, hypothyroidism, diabetes mellitus, chronic kidney disease, osteoarthritis, and chronic obstructive pulmonary disease receive care from long-term care nurses. Patients with progressive illnesses such as Alzheimer's disease, multiple sclerosis, Parkinson's disease, and AIDS wasting complex are also cared for by long-term care nursing staff. All of the reasons mentioned create the need for diversity in the workforce. This is especially true with RNs because they often work in leadership roles cross functionally within the organization.

\section{Pharmacists}

Pharmacists provide a variety of services within the LTC setting. Pharmacy is another broad area, and depending on the type of pharmacy, it will determine how the patients are serviced. The pharmacy has tiered roles, including pharmacy technicians, and pharmacists have varying levels of professional responsibilities.

The role of a long-term care pharmacist is broad and varied. In long term care environments, the pharmacist's role is described as a dispensing pharmacist or consultant pharmacist. Dispensing pharmacists provide services that are less clinical and typically operate inhouse. In the dispensing role, the pharmacist is expected to prepare medications by reviewing and interpreting physician orders, detecting therapeutic incompatibilities and possible interactions between drugs, dispensing medications by compounding, packaging, and labeling pharmaceuticals, controlling medications by monitoring drug therapies and advising interventions. The pharmacist also is expected to complete pharmacy operational requirements, such as organizing and directing technicians' work flow, verifying technician preparation and labeling of pharmaceuticals, verifying order entries, charges, and inspections, and answering questions and requests made by health care professionals. Consultant pharmacists are integrated into the clinical team and work alongside of the prescribing physician. The consultant pharmacist may have responsibilities that take them outside of the actual facility as they may travel within a geographic area in order to service patients.

Educationally, the standard for becoming a pharmacist has now changed to a PharmD (Doctor of Pharmacy) degree. There may still be limited numbers of pharmacists who have BSPharm degrees in pharmacy; however, to secure a license to practice pharmacy, they must pass the NAPLEX exam, MPJE, and in some states, compounding medications is required. Pharmacists can attain additional board certifications in specialty areas, which includes geriatric pharmacy (https://www.bpsweb.org/bps-specialties/).

\section{Pharmacy Technicians}

Pharmacy technicians are usually required to be certified. Pharmacy technicians are not required by law to receive additional education beyond high school; however, the standard does require that they register with the state's board to work as a pharmacy technician. These requirements vary by state and select states require technicians to be nationally certified. Typically, the pharmacy technician's role requires a great deal of flexibility. Even if the state does not require pharmacy technicians to be certified, some employers may require it. The Pharmacy Technician Certification Board, for example, awards the Certified Pharmacy Technician (CPhT) credential to qualified candidates who pass a national certification exam (www.ptcb.org). CPhTs must recertify every two years by earning 20 continuing education credits. 


\section{Paraprofessionals}

Paraprofessionals include home health aides, nursing aide/assistants (CNA's), orderlies and personal and home care aids as well as those employed as independent providers by consumers. CNAs are often called the eyes/ears of the environments in which they work because they see the patients often. Educationally, the standard typically required a CNA to hold a certificate in the state in which they are working and their names need to appear on the State Nurse Aid Registry. According to the Nursing Assistant Guide, there tends to be a high rate of turnover for CNA positions, which makes it easy to find work. The demand for CNAs is high, especially among establishments that supply continuing treatment and assisted living to elderly patients. A CNA will have many tasks and duties because the work will be with patients that have various levels of health.

Some of the tasks outside of the routine duties of a CNA in a long-term care facility include helping to record patient vital signs and other details and making contact with a nurse or doctor when there is a decline in a patient's health or if they are developing a new illness, complication or injury. CNAs may also have the responsibility of some residents that will require assistance to completely bathe, dress, groom and/or feed them so that they can eat safely. These nursing assistants play an important role in helping patients avoid the development of bedsores, which is a very big part of maintaining quality care that is expected for all patients. If patients are able to be mobile on their own, CNAs help them get up and moving to avoid being in one position too long. If residents are not mobile, CNAs help rotate and move them to prevent bedsores. In some cases, the CNA might be helping to deliver medication to patients. This will depend on regulations in the state and the facility in which they work. CNAs also may change dressings for patients who need wound care and perform other basic first aid care.

\section{Home Health Care}

Home health is provided to patients who are confined to the home when services are ordered by a physician. Home Health services are provided by CNA's, LPNs and RN's and the number of hours can be determined by the time spent with each patient. Skilled services can be provided at a patient's home or in an LTAC or at the patient's home. It is based on the level of care that the patient needs. Acute, skilled or long term. Although home health is not technically LTC, many times it is provided over a 30-day episode and to individuals who are in LTC services. Home health services are often part of LTC companies.

\section{CASE DESCRIPTION AND METHODS}

This case describes a long-term care organization that was founded with a single skilled nursing facility and a servicing pharmacy. The founder recognized the advantages of combining a nursing home with a pharmacy since most long-term care patients were typically prescribed multiple prescription medications. The organization remains a privately-owned organization which has applied the same economic advantages of vertical integration as it grew. With acquisition of additional skilled nursing facilities, the organization vertically integrated other long-term care related organization types to include rehabilitation, medical supplies, home health care, and hospice companies. Case management services were added to coordinate patient care with payment providers. Naturally, additional growth occurred in the pharmacy organization to accommodate geographic spread and state regulations.

With the growth through vertical integration of the organization, corporate support was added. Ultimately, this support required over 200 employees. Innovative leadership of the organization orchestrated a strategic plan that focused on growth through acquisition, 
modernization of facilities and equipment, and debt liquidation over a planning period of more than ten years. The organization developed a marketing strategic plan and implemented an administrator-in-training program to fill a growing number of long-term care administrative positions.

Other innovations included the selection and purchase of an enterprise resource planning system (ERP) to include financial and human resource systems. This initiative required more than two years to implement and included an impressive expansion of the information technology department. A centralization effort in this long-term care organization involved streamlining the administrative functions of the operating units and the enlargement of these functions at the corporate level. Such things as billing, accounts receivable, accounts payable, and human resource management received attention during the centralization process.

Marketing was an emphasis following the ERP and centralization implementations. This emphasis involved a re-branding of the organization and the vertically integrated organizational elements. The management interest in marketing received a great deal of attention during which census was emphasized. Case mix was strategically emphasized, with Medicare paid rehabilitation emphasized during budgeting and admissions marketing. With pay-for-performance, these elements received priority value. Financial objectives were emphasized with marketing, case mix, census, billing, and accounts payable management receiving more attention and weight.

The result of these organizational priorities over several years had an unintended effect on human resource management. By placing attention on so many areas, and by including them in a pay-for-performance plan, little time and energy were left for the operating unit leaders to focus on the human resource needs of the operating units. By default, the inability to attend to many human resource basics ultimately led to degrading employee satisfaction and a lack of emphasis on achieving diversity.

The EE01 Report was mandated by Title VII of the Civil Rights Act of 1964. It is required for all private employers who are subject to Title VII of the Civil Rights Act of 1964 (as amended by the Equal Employment Opportunity Act of 1972) with 100 or more employees excluding state and local governments, primary and secondary school systems, institutions of higher education, Indian tribes and tax-exempt private membership clubs other than labor organizations. It also excludes organizations that are subject to Title VII and have fewer than 100 employees if the company is owned or affiliated with another company, or there is centralized ownership, control or management (such as central control of personnel policies and labor relations) so that the group legally constitutes a single enterprise, and the entire enterprise employs a total of 100 or more employees.

Additionally, all federal contractors (private employers), who are not exempt as provided for by 41 CFR 60-1.5, have 50 or more employees, and are prime contractors or first-tier subcontractors, and have a contract, subcontract, or purchase order amounting to $\$ 50,000$ or more, or serve as a depository of Government funds in any amount, or is a financial institution which is an issuing and paying agent for U.S. Savings Bonds and Notes.

The EE01 Report is regulated by the Equal Employment Opportunity Commission (EEOC) and the Office of Federal Contract Compliance Programs (OFCCP) in the Federal Department of Labor. During the data collection, the standard Equal Employment Opportunity Commission terms and methods for the creation of the organization's annual EE01 Report were used. Further analysis using frequency and distribution-oriented statistics has allowed a more in- 
depth review of this organization's level of diversity in each of its vertically integrated companies. The second level of analysis using comparative statistics allowed the illustration of the internal level of consistency within the organization.

\section{ANALYSIS}

Data were collected using the standard Equal Employment Opportunity Commission terms and methods for the creation of the organization's annual EE01 report. Further analysis using frequency and distribution-oriented statistics allowed a more in-depth review of this organization's level of diversity in each of its vertically integrated companies. The second level of analysis using comparative statistics allowed the illustration of the internal level of consistency within the organization.

The total number of employees included in this case is 12,401 . The largest number of workers are in skilled nursing facilities (SNFs), 9207. Females make up 87 percent of the SNFs, and males the remaining 13 percent. Table 1 describes the number and percent of employees by gender working in each type of subsidiary and level of the Company. Females range from 8797 percent of the workforce in skilled nursing facilities, assisted living and respite care. Males make up 75 percent of building management. Males are a minority in the entire company representing only 14 percent of total employees.

Table 1 - Frequency

Sex by Company Type

\begin{tabular}{|l|c|c|c|}
\hline Count (\%) of Sex & \multicolumn{1}{l|}{ Sex } & & \\
\hline Company Type & Female & Male & Grand Total \\
\hline ALC & $118(96 \%)$ & $5(4 \%)$ & 123 \\
\hline Building Mgt & $22(25 \%)$ & $67(75 \%)$ & 89 \\
\hline Case Management & $81(92 \%)$ & $7(8 \%)$ & 88 \\
\hline Clinical Consulting & $109(87 \%)$ & $17(13 \%)$ & 126 \\
\hline Corporate & $314(75 \%)$ & $142(25 \%)$ & 416 \\
\hline Food Supplies & $25(71 \%)$ & $10(2 \% \%)$ & 35 \\
\hline Home Care & $178(92 \%)$ & $15(8 \%)$ & 193 \\
\hline Hospice & $553(88 \%)$ & $74(12 \%)$ & 627 \\
\hline Med Supplies & $15(47 \%)$ & $17(53 \%)$ & 32 \\
\hline Nutritional & $8(89 \%)$ & $1(11 \%)$ & 9 \\
\hline Pharmacy & $174(76 \%)$ & $56(24 \%)$ & 230 \\
\hline Rehab & $861(84 \%)$ & $161(16 \%$ & 1022 \\
\hline Respite & $34(97 \%)$ & $1(3 \%)$ & 35 \\
\hline SNF & $7993(87 \%)$ & $1214(13 \%)$ & 9207 \\
\hline SOURCE & $124(96 \%)$ & $5(4 \%)$ & 129 \\
\hline Grand Total & $10609(86 \%)$ & $1792(14 \%)$ & 12401 \\
\hline
\end{tabular}

Table 2 shows the frequency and percentage of categories of workers in each company type. Combined, corporate and skilled nursing companies had the largest number of executive/senior management employees, 519 in skilled nursing and 110 in corporate; however, in skilled nursing they made up only 6 percent of the workforce as opposed to $26 \%$ in corporate. 
Table 2 - Frequency (\%)

Job Type by Company Type

\begin{tabular}{|c|c|c|c|c|c|c|c|}
\hline Count of Job Function & Job Function & & & & & & \\
\hline Assisted Living & $4(3 \%)$ & $4(3 \%)$ & $99((80 \%)$ & $1(1 \%)$ & $15(12 \%)$ & & 123 \\
\hline Case Management & $5(6 \%)$ & $58(66 \%)$ & & $21(24 \%)$ & $4(5 \%)$ & & 88 \\
\hline Clinical Consulting & $9(7 \%)$ & $102(81 \%)$ & & $6(5 \%)$ & $9(7 \%)$ & & 126 \\
\hline Food Supplies & $2(6 \%)$ & $1(3 \%)$ & & & $32(91 \%)$ & & 35 \\
\hline Home Care & $21(11 \%)$ & $105(54 \%)$ & $24(12 \%)$ & $21(11 \%)$ & $22(11 \%)$ & & 193 \\
\hline Hospice & $48(8 \%)$ & $322(51 \%)$ & $163(26 \%)$ & $45(7 \%)$ & $49(8 \%)$ & & 627 \\
\hline Med Supplies & $2(6 \%)$ & $1(3 \%)$ & $5(16 \%)$ & $4(13 \%)$ & $20(63 \%)$ & & 32 \\
\hline Rehab & $7(1 \%)$ & $653(64 \%)$ & $295(29 \%)$ & & $67(7 \%)$ & & 1022 \\
\hline Respite & $1(3 \%)$ & $2(6 \%)$ & $31(89 \%)$ & & $1(3 \%)$ & & 35 \\
\hline Skilled Nursing & $519(6 \%)$ & $2390(26 \%)$ & $3851(42 \%)$ & $59(1 \%)$ & $2280(25 \%)$ & $108(1 \%)$ & 9207 \\
\hline SOURCE & $13(10 \%)$ & $91(71 \%)$ & & $24(19 \%)$ & $1(1 \%)$ & & 129 \\
\hline Grand Total & $764(6 \%)$ & $3926(32 \%)$ & $4716(38 \%)$ & $193(2 \%)$ & $2694(22 \%)$ & $108(1 \%)$ & 12401 \\
\hline
\end{tabular}

By far, the largest number of first line and middle management and professional positions were in skilled nursing. These management positions made up $26 \%$ of the workforce in skilled nursing and professional positions made up $42 \%$ of the total skilled nursing company 9,207 employees.

Table 3 shows the number and percent of ethnic groups by job type throughout the organization. These tables represent the organization's racial and ethnic diversity across job types. Hispanics, Asians, and others make up only 4 percent of the entire organization across all job types, 551 of the total 12,401 employees. Blacks make up 55 percent and whites the remaining 40 percent. Blacks make up 78 percent of laborers, 70 percent of sales and marketing jobs, and 65 percent of professional jobs, but only 39 percent of first and mid-level manager positions. Whites hold 55 percent of the first and middle level manager positions and 69 percent of executive and senior level jobs.

Table 3- Frequency (\%)

Ethnic Group by Job Type

\begin{tabular}{|l|c|c|c|c|c|c|}
\hline Count of Ethnic Group & Ethnic Group & & & & \\
\hline Job Function & ASIAN & BLACK & HISPA & OTHER & WHITE & Grand Total \\
\hline Executive/Senior & $6(1 \%)$ & $220(29 \%)$ & $5(1 \%)$ & $7(1 \%)$ & $526(69 \%)$ & 764 \\
\hline First/Mid Level Mgr. & $95(2 \%)$ & $1544(39 \%)$ & $29(1 \%)$ & $93(2 \%)$ & $2165(55 \%)$ & 3926 \\
\hline Laborers & & $84(78 \%)$ & $1(1 \%)$ & $11(10 \%)$ & $12(11 \%)$ & 108 \\
\hline Professionals & $33(1 \%)$ & $3071(65 \%)$ & $48(1 \%)$ & $93(2 \%)$ & $1471(31 \%)$ & 4716 \\
\hline Sales/Marketing & $11(0 \%)$ & $1880(70 \%)$ & $79(3 \%)$ & $32(1 \%)$ & $692(26 \%)$ & 2694 \\
\hline Technicians & $3(2 \%)$ & $60(31 \%)$ & $2(1 \%)$ & $3(2 \%)$ & $125(65 \%)$ & 193 \\
\hline Grand Total & $148(1 \%)$ & $6859(55 \%)$ & $164(1 \%)$ & $239(2 \%)$ & $4991(40 \%)$ & 12401 \\
\hline
\end{tabular}


Table 4 describes the frequency and percentage of employees by gender and job type. Females make up the vast majority of the organization, 10,609 of the 12,401 employees, or 86 percent. Males make up the remaining 14 percent, 1792. Females also represent 90 percent of professionals, 89 percent of first and middle management positions, 80 percent of technicians, 78 percent of sales and marketing, and 68 percent of laborers. Beside the laborer category, the lowest female representation is 70 percent in the executive and senior management positions.

\begin{tabular}{|c|c|c|c|}
\hline \multicolumn{4}{|c|}{$\begin{array}{c}\text { Table } 4 \text { - Frequency (\%) } \\
\text { Sex by Job Type }\end{array}$} \\
\hline Count of Sex & Sex & & \\
\hline Job Function & $\mathrm{F}$ & $M$ & Grand Total \\
\hline Executive/Senior & $\begin{array}{c}534 \\
(70 \%)\end{array}$ & $\begin{array}{c}230 \\
(30 \%)\end{array}$ & 764 \\
\hline First/Mid Level Mgr. & $\begin{array}{c}3501 \\
(89 \%)\end{array}$ & $\begin{array}{c}425 \\
(11 \%)\end{array}$ & 3926 \\
\hline Laborers & $\begin{array}{c}73 \\
(68 \%) \\
\end{array}$ & $\begin{array}{c}35 \\
(32 \%) \\
\end{array}$ & 108 \\
\hline Professionals & $\begin{array}{c}4232 \\
(90 \%)\end{array}$ & $\begin{array}{c}484 \\
(10 \%)\end{array}$ & 4716 \\
\hline Sales/Marketing & $\begin{array}{c}2114 \\
(78 \%) \\
\end{array}$ & $\begin{array}{c}580 \\
(22 \%)\end{array}$ & 2694 \\
\hline Technicians & $\begin{array}{c}155 \\
(80 \%) \\
\end{array}$ & $\begin{array}{c}38 \\
(20 \%) \\
\end{array}$ & 193 \\
\hline Grand Total & $\begin{array}{l}10609 \\
(86 \%) \\
\end{array}$ & $\begin{array}{c}1792 \\
(14 \%) \\
\end{array}$ & 12401 \\
\hline
\end{tabular}

\section{DISCUSSION}

The analysis presents an organization that is typical of long term care organizations. Health care is over represented by females because the nursing profession has traditionally been mostly a female occupation. Although effort has been made to increase diversity in nursing programs (Kovner, C.T, Djukic, M., Jun, J., Fletcher, J., Fatehi, F.K. and Brewer, C.S., 2018), it has been reported that males represent only 8 percent of nurses in the U.S. (Budden, J., Moulton, P., Harper, K., Brunell, M.L., and Smiley, R., 2016). It is, therefore, not surprising that females make up the vast majority of employees in this organization with males representing 10 percent of professionals. This under representation of males is the result of a systematic professional issue.

It might be expected that executive senior level gender representation would mirror the nursing profession. But in this case, males make up 30 percent of upper management while representing only 10 percent of professionals, and 14 percent of the total organization. Males can be considered over-represented in the executive and senior levels; however, this is not unlike other corporate settings in health care and other business settings.

Racial diversity is another issue facing health care organizations. African American make up 55 percent of the employees of this organization, whites 40 percent, and other ethnic groups make up the remaining 5 percent. Although this study does not have comparative data, it is suggested that this racial and ethnic profile can be considered representative of the demographics of the population of its facilities.

This study raises several questions related to diversity in health care and especially long term care organizations.

1) Does the organization's nursing workforce mirror the population being served? 
2) Does the employee mix of the organization represent the population being served?

3) Do ethnic and gender profiles match the general population?

4) Do ethnic and gender profiles match the nursing profession?

5) Do executive and senior level management positions profiles match the organization's ethnic and gender profiles?

\section{CONCLUSIONS}

Achieving diversity continues to be one of the main human resource management problems among health care organizations. In the long-term care arena, diversity can be even more exacerbating problem. The limitations include the population diversity from which employees come. In addition, the development and implementation of corporate HR policies directly impact the level of diversity achieved.

This case study calculates and analyses the diversity of a vertically integrated long-term care organization operating in several states. The data were collected from a single long-term care organization operating in multiple states and employing over 13,000 employees. The vertically integrated health care companies include home health care, hospice, rehabilitation, skilled nursing, medical supply, pharmacy, and the corporate entity. In this case, the data collected were for use in the annual EE01 report and during a consulting engagement. The results show that this organization, although racially diverse, lacks diversity in executive and senior level management.

\section{References}

Bates, T., Amah, G., Coffman, J. (2018) Racial/Ethnic Diversity in the Long - term Care Workforce. San Francisco, CA: UCSF Health Workforce Research Center on Long - Term Care

Betancourt, J., Beiter, S., Landry, A. (2013). Improving Quality, Achieving Equity, and Increasing

Diversity in Healthcare: The Future is Now. Journal of Best Practices in Health Professions Diversity: Education, Research \& Policy. Spring2013, Vol. 6 Issue 1, p903-917. 15p.

Budden, J., Moulton, P., Harper, K., Brunell, M.L., and Smiley, R. (2016). The 2015 national nursing workforce survey. Journal of Nursing Regulation, 7(1), S1-S90.

Cooper, L.A., Roter, D.L., Johnson, R.L., Ford, D.E., Steinwachs, D. M., \& Powe. N. R. (2003). Patient-Centered Communication, Ratings of Care, and Concordance of Patient and Physician Race. Ann Intern Med. 139(11), 907915.

Health Literacy: A Prescription to End Confusion, (2004), Institute of Medicine (US) Committee on Health Literacy; Nielsen-Bohlman L, Panzer AM, Kindig DA, editors. Washington (DC). Institute of Medicine. (2003). Unequal treatment: Confronting racial and ethnic disparities in health care. Washington, DC: National Academy Press.

Institute of Medicine (2004). In the nation's compelling interest: Ensuring diversity in the health care workforce. Washington, DC: National Academy Press.

Institute for Diversity in Health Management. (2018). About the Institute. Available at: http://www.diversityconnection.org/diversityconnection/about-us/About-the-Institute.jsp.

Institute for Diversity in Health Management. (2015). Diversity and disparities: A benchmarking study of U.S. hospitals in 2015. Retrieved from: http://www.diversityconnection.org/diversityconnection/leadershipconferences/2016 Conference Docs and Images/Diverity_Disparities2016_final.pdf

Kovner, C.T, Djukic, M., Jun, J., Fletcher, J., Fatehi, F.K. \& Brewer, C.S. (2018). Diversity and education of the nursing workforce 2006-2016. Nursing Outlook, 66, 160-167.

Noble, D, Greenhalgh, T, Casalino, LP. (2014). Improving population health one person at a time? Accountable care organisations: perceptions of population health-a qualitative interview study. BMJ Open 2014;4

Sullivan Commission on Diversity in the Healthcare Workforce. (2004). Missing persons: Minorities in the health professions. Retrieved from: http://health-equity.lib.umd.edu/40/1/Sullivan_Final_Report_000.pdf 
Sullivan Luallin Group, (2013). Healthcare professionalism: How important is proper bedside manner? Retrieved from https://sourcesouthuniversity.edu/healthcare-professionalism-how-important-is-proper-bedside-manner132067.aspx.

Svantesson M, Carlsson E, Prenkert M, et al, (2016). 'Just so you know, the patient is staff': healthcare professionals' perceptions of caring for healthcare professional-patients. BMJ Open 2016;6

Understanding cultural diversity in health care, Retrieved from https://www.ggalanti.org/ cultural-diversity-inhealthcare/ on 11/05/2018.

Van Keer, R., Deschepper, R., Francke, A., Huyghens, L., \& Bilsen, J. (2015). Conflicts between healthcare professionals and families of a multi-ethnic patient population during critical care: an ethnographic study. Critical Care 19:441.

Weech-Malddonado, R., Dreachslin, J.L., Dansky, K.H., DeSouza, G., \& Gatto, M. (2002). Racial/ethnic diversity management and cultural competency: The case of Pennsylvania hospitals. Journal of Healthcare Management, 47(2), 111-124.

Wilson-Stronks, A., and Mutha, S. (2010). From the perspective of CEOs: What motivates hospitals to embrace cultural competence? Journal of Healthcare Management, 55(5), 339-351.

United States Department of Health and Human Services, Office of Minority Health. (2013). National standards for culturally and linguistically appropriate services in health care: A blueprint for advancing and sustaining CLAS Policy and Practice. Retrieved from www.thinkculturally.hhs.gov. 